\title{
AUTHOR CORRECTION OPEN \\ Correction: Lymphopenia predicts disease severity of COVID-19: a descriptive and predictive study
}

Li Tan, Qi Wang, Duanyang Zhang, Jinya Ding, Qianchuan Huang, Yi-Quan Tang, Qiongshu Wang and Hongming Miao

Signal Transduction and Targeted Therapy (2020)5:61

; https://doi.org/10.1038/s41392-020-0159-1

Correction to: Signal Transduction and Targeted Therapy https:// doi.org/10.1038/s41392-020-0148-4, published online 27 March 2020

Since the publication of this article, ${ }^{1}$ we noticed a minor mistake in the reference that needs to be corrected.

To support the clinical manifestation "metabolic acidosis" in the COVID-19, in the fifth sentence of paragraph one, we cited an inappropriate reference 4 "Huang, C. et al. Clinical features of patients infected with 2019 novel coronavirus in Wuhan, China. Lancet. 395, 497-506, (2020)" which needs to be replaced with Diagnosis and Treatment Protocol for COVID-19 (Trial Version 5) published by National Health Commission of the People's Republic of China.

The key messages of the article are not affected by this correction. We apologize for this inadvertent mistake.

\section{REFERENCE}

1. Tan, L. et al. Lymphopenia predicts disease severity of COVID-19: a descriptive and predictive study. Sig. Transduct. Target Ther. 5, 33, https://doi.org/10.1038/s41392020-0148-4 (2020).

\begin{abstract}
Open Access This article is licensed under a Creative Commons adaptation, distribution and reproduction in any medium or format, as long as you give appropriate credit to the original author(s) and the source, provide a link to the Creative Commons license, and indicate if changes were made. The images or other third party material in this article are included in the article's Creative Commons license, unless indicated otherwise in a credit line to the material. If material is not included in the article's Creative Commons license and your intended use is not permitted by statutory regulation or exceeds the permitted use, you will need to obtain permission directly from the copyright holder. To view a copy of this license, visit http://creativecommons. org/licenses/by/4.0/.
\end{abstract}

(c) The Author(s) 2020 